\title{
Association of relative food availabilities and locations by
} cattle

\author{
D.W. BAILEY, L.R. RITTENHOUSE, R.H. HART, D.M. SWIFT, AND R.W. RICHARDS
}

\begin{abstract}
Four yearling steers were trained and observed in a parallel-arm maze. The purpose was to determine if cattle had the abllity to associate locations with relative food avallabilities. The study consisted of 3 phases. In phase 1 , all 5 arms contained $0.4 \mathrm{~kg}$ of grain. In phase 2, the amount of grain in each arm was systematically varied from 0.1 to $0.8 \mathrm{~kg}$. In phase 3 , placement of grain was reversed. Steers performed efiiciently in all 3 phases of the study. The overall-mean number of correct choices in the first 5 entrances was 4.69 as compared to 3.73 by chance. Arms selected for choices 2,3 , and 4 during the last 5 trials of phase 2 were different $(P<0.05)$ from those selected during the last 5 trials of phase 3. For the last 5 trials of phases of 2 and 3 , arms selected in choices 1,2 , and 3 contained $0.4,0.6$ and $0.8 \mathrm{~kg}$ of grain on $85 \%$ of the trials. Steers appeared to order their choices from larger to smaller rewards. Steers apparently can remember not only where they have foraged, but also the amount of food found there.
\end{abstract}

Key Words: spatial memory, cattle, maze, food availability

Regression models have been used to predict grazing distribution patterns of livestock with variable success (Cook 1966, Miller and Krueger 1976, Senft et al. 1983). Gillen et al. (1984) were not able to predict grazing distribution patterns with useful precision. The authors speculated that grazing distribution patterns were difficult to predict because they were influenced by a complex of physical and biological factors.

Cattle tend to avoid steep slopes and to avoid traveling a long distance from water or salt (Cook 1966, Mueggler 1965). These physical factors may act as constraints and subsequently limit animal distribution. Livestock also responded to forage quantity and forage quality. Large herbivores appear to match the time spent foraging in a plant community with the forage resources of the community (Senft et al. 1987). Although this matching pattern has been described, the underlying mechanisms or behaviors that explain this response pattern are not completely understood. In order to predict nutrient removal in different habitats, hypothetical mechanisms or spatial-decision rules that herbivores might utilize should be developed and tested.

One possible mechanism is that herbivores return to nutrientrich, productive plant communities more often than to lessproductive plant communities. This mechanism requires that herbivores have the ability to remember where they have foraged and the resource level that was found there. Bailey et al. (1987) found that cattle have an accurate spatial memory in radial-and parallelarm mazes. Other animal species, such as rats and pigeons, have also performed accurately and efficiently in radial-arm mazes (Olton 1978, Roberts and Van Velduizen 1985). Rats and pigeons can learn to distinguish among quantities of food associated with 4 different arms in a radial maze and order their arm choices from

\footnotetext{
Authors are former graduate research associate and professor, Range Science Department, Colorado State Univeristy, Fort Collins 80523; range scientist, USDAARS, High Plains Grasslands Research Station, Cheyenne, Wyoming 82001; associate professor, Range Science Department, Colorado State University; professor, Department of Psychology, Colorado State University. Research was funded in part by the Colorado state University Agricultural Experiment Station, Project 150771.

Manuscript accepted 9 March 1989.
}

largest to smallest reward (Hulse and O'Leary 1982, Roberts and Van Veldhuizen 1985). This is evidence that they can remember where they have foraged and the amount of food found there.

The objectives of this study were to determine if cattle could distinguish and remember the amount of feed consumed in different arms of a parallel maze and use that informtion for selecting arms during the next trial on the following day.

\section{Materials and Methods}

Two sets of monozygous-twin yearling steers were trained and observed in a 5-arm, parallel maze. One set was Angus $X$ Hereford (10A and 10B), and the other set was Barzona $\times$ Hereford (15A and 15B). These steers had previously been trained in a radial-arm maze (Bailey 1988). This maze was constructed in a Russian wildrye (Elymus junceus) pasture using electric fence. The maze was composed of a decision area $(51 \times 9 \mathrm{~m})$ and 5 arms $(37.5 \mathrm{~m}$ in length). The gate was located directly across the decision area from arm (Fig. 1).

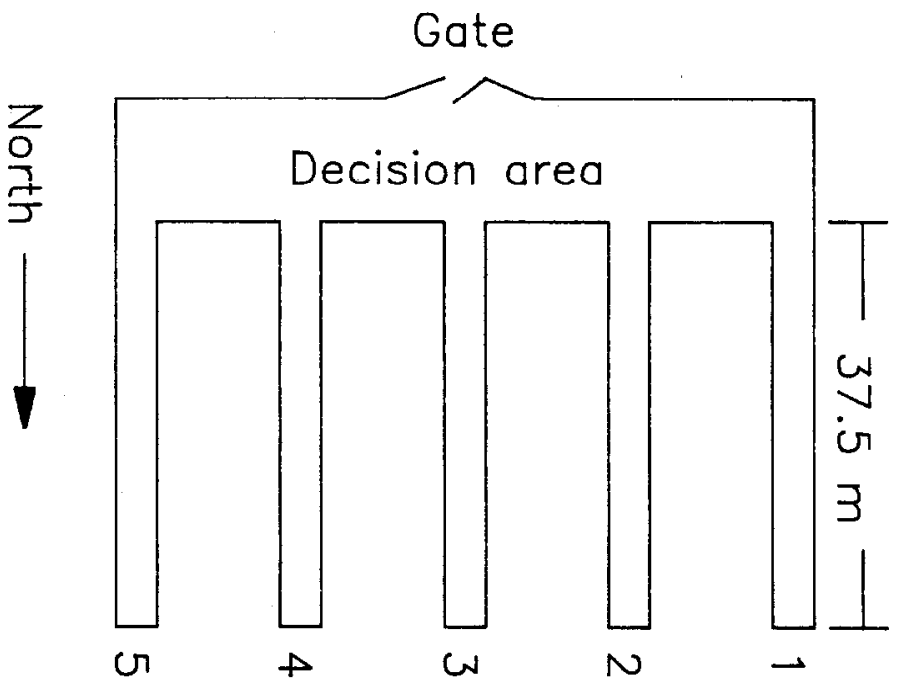

Fig. 1. Five-arm parallel maze.

Preliminary training consisted of guiding each steer into the decision area, assisting it down each arm, and allowing it to consume the $0.4 \mathrm{~kg}$ of grain mix placed in an opaque feeder at the end of each arm. This was continued once per day for 5 days to familiarize the steers to the maze.

After preliminary training, a trial consisted of guiding a steer into the decision area and allowing it to freely choose arms until all grain was consumed. If the animal had not consumed all the grain within $40 \mathrm{~min}$, the steer was assisted (herded) into an arm still containing grain. If the observer only started the animal moving and avoided influencing its choice, a push was recorded, and the 
subsequent choice was termed non-assisted. A correct choice was defined as entry into a previously unentered arm without assistance followed by consumption of grain. A mistake or repeat was defined as entry into an arm where grain had been consumed previously. Each steer was placed in the maze and observed daily until the end of the study, and the order of placement was randomized. During the interval between observation periods, steers were kept in a nearby pasture. To minimize the chance of steers using grain odor for a cue in arm selection, additional grain $(0.4 \mathrm{~kg})$ was placed at the end of each arm. This grain was placed in an open container behind the feeder and beyond the reach of the steer.

The study consisted of 3 phases that were distinguished by the amount and location of grain. For the first 5 days (phase 1), $0.4 \mathrm{~kg}$ of grain was placed at the end of each arm. During the next 7 days (phase 2), steers within each identical-twin set were randomly assigned to either the ascending or the descending treatment. For the ascending treatment, $0.1,0.2,0.4,0.6$, and $0.8 \mathrm{~kg}$ of grain were placed in arms $1,2,3,4$, and 5 (Fig. 1), respectively. For the descending treatment, $0.8,0.6,0.4,0.2$, and $0.1 \mathrm{~kg}$ of grain were placed in arms $1,2,3,4$, and 5 , respectively. At the end of phase 2 , animals were switched to the other treatment for 10 days (phase 3 ).

Sign tests (Conover 1980) were used to compare arms chosen on choices 1 to 5 between identical twins for the last 5 trials of phases 2 and 3. Signs had to be reversed in phase 3 in order to pool responses from phases 2 and 3 , because of the crossover type of experimental design. A difference in the order of arm choices between identical twins could indicate the ability of cattle to use spatial memory to distinguish among locations with various levels of reward.

Sign tests were also used to compare arms selected by a steer for choices 1 to 5 for the last 5 days of phases 2 and 3. Results from both steers in a treatment group (ascending-descending or descendingascending) were pooled and analyzed together. This analysis compares arm selection of a steer (not a comparison between twins) during phase 2 and 3 . A difference in order of choices during phase 2 and 3 would indicate that steers can form (and later modify) associations between locations and levels of reward.

For both statistical analyses described above, the primary emphasis should be given to choices 2 and 3. Gate location may have biased the first arm chosen. Choices 4 and 5 were occasionally incorrect which could also confound the results.

Spearman's rho rank correlation coefficient (Conover 1980) was used to compare the sequence of arm selection. The arm numbers (Fig. 1) were used as ranks. The rank correlation coefficient was used as an indicator of the relationship between 2 sequences of arm choices.

\section{Results and Discussion}

The steers performed very efficiently in all 3 phases of the study (Table 1). The overall-mean number of correct choices in the first 5 entrances was 4.69. The number of correct choices in the first 5 entrances that would be expected by chance was 3.73 (calculated from equations from Beatty and Shavalia 1980). The steers

Table 1. Mean performance of steers in a 5-arm parallel maze with equal (phase 1), varied (phase 2) and reversed (phase 3) rewards.

\begin{tabular}{lccc}
\hline \hline Phase & $\begin{array}{c}\text { Number } \\
\text { of trials }\end{array}$ & $\begin{array}{c}\text { Correct choices } \\
\text { in first } \\
\text { 5 entrances }\end{array}$ & $\begin{array}{c}\text { Total incorrect } \\
\text { choices }\end{array}$ \\
\hline 1 & 20 & 4.70 & 0.35 \\
2 & 28 & 4.54 & 0.71 \\
3 & 40 & 4.80 & 0.33 \\
Overall & 88 & 4.69 & 0.45 \\
\hline
\end{tabular}

The number of arms that would be entered correctly by chance alone is 3.73 (calculated by methods presented by Beatty and Shavahia 1980). required very little assistance from the observers. On 2 occasions, a steer was herded into an arm still containing grain after a 40-mintime period had been exceeded (assist). On 5 trials, a steer was started moving (push) after the time period was exceeded. Assistance from the observer was required only for the last choice.

Of greater importance was the order in which the arms were chosen. Arm 3 (nearest to the entrance gate) was the first arm chosen in $93 \%$ of the trials. In phase 2, all steers quickly learned to choose arms containing $0.8,0.6$ or $0.4 \mathrm{~kg}$ of grain in the first 3 choices. During the last 5 trials of phases 2 and $3,85 \%$ of the first 3 choices were of arms that contained $0.8,0.6$, and $0.4 \mathrm{~kg}$ of grain (Table 2). These arms would be expected to be selected for the first

Table 2. Sequence in which various amounts of grain (kg) were consumed in the hast 5 trials of phases 2 and 3.

\begin{tabular}{lcc}
\hline \hline Sequence* & $\begin{array}{c}\text { Sequence } \\
\text { frequency }\end{array}$ & $\begin{array}{c}\text { Percent of } \\
\text { total trials }\end{array}$ \\
\hline .4 .8 .6 .2 .1 & 11 & 27.5 \\
.4 .6 .8 .2 .1 & 11 & 27.5 \\
.6 .8 .1 .2 .2 & 9 & 22.5 \\
.6 .8 .4 .1 .2 & 2 & 5.0 \\
.4 .8 .6 .1 .2 & 1 & 2.5 \\
.4 .8 .2 .6 .1 & 1 & 2.5 \\
.4 .6 .2 .1 .8 & 1 & 2.5 \\
.4 .2 .8 .6 .1 & 1 & 2.5 \\
.4 .2 .6 .8 .1 & 1 & 2.5 \\
.4 .1 .8 .6 .2 & 1 & 2.5 \\
.4 .2 .1 .6 .8 & 1 & 2.5 \\
Total & 40 & 100.0 \\
\hline
\end{tabular}

Incorrect choices were not included in this analysis. There were no incorrect choices in the first 3 entrances.

3 choices on $10 \%$ of the trials by chance. Few errors made in phases 2 and 3 involved reentering arms that contained 0.1 or $0.2 \mathrm{~kg}$ of grain. Arms which had contained $0.8,0.6$, and $0.4 \mathrm{~kg}$ of grain accounted for 32,26 , and $32 \%$ of incorrect choices, respectively.

Twins selected different $(P<0.05)$ arms for choices 2,3 , and 4 in the last 5 trials of phases 2 and 3 . There was no difference between twins $(P>0.05)$ in arms selected for choices 1 and 5 .

Arms selected for choices 2, 3, and 4 of phase 2 were different $(P<0.05)$ from those chosen in phase 3 for steers in both the ascending-descending (steers $10 \mathrm{~A}$ and 15B) and descendingascending (steers $10 \mathrm{~B}$ and 15A) treatments. Arm selection on choice 5 was different $(P<0.05)$ for the descending-ascending treatment but not for the ascending-decending treatment $(P>0.05)$. There was no difference $(\boldsymbol{P}>0.05)$ in arms selected for choice 1 for either treatment.

Rank correlation analysis of the entire choice sequence generally agreed with the separate analysis of each choice. The correlation, however, added little to interpretation of choice sequences and was removed from this presentation.

Steers may not have distinguished among all quantities of grain, but they definitely avoided arms that contained 0.1 or $0.2 \mathrm{~kg}$ of grain until the fourth and fifth choices. Steers may have divided arms into those containing higher or lower quantities of grain. Steers quickly learned the quantity of grain (high or low) associated with each arm. It took somewhat longer for the steers to change their choice sequence when the placement of grain was reversed (phase 3 ). The preference for higher quantities of grain did not overcome steers's bias for choosing the arm directly in front of the gate in choice 1 .

Efficient performance of the steers indicates that they have an accurate spatial memory (Bailey et al. 1987). Animals apparently use working memory to remember which arms were visited (Olton 1978). Specific stimuli and responses that are required for a given trial are stored in working memory and can be forgotten at the end 
of a trial. The location of each arm and the fact that each arm contains a certain amount of food at the beginning of a trial are stored in long-term or reference memory (Honig 1978). Rats and pigeons apparently can store in reference memory which arms of a maze contain food and the amount of food consumed in each arm (Hulse and O'Leary 1982, Roberts and Van Veldhuizen 1985). Results from this study indicate that cattle can develop reference memory that also includes information on the relative amount of food contained in each arm.

As in the study by Hulse and O'Leary (1982), animals reentered arms that contained larger amounts of food more often than arms that contained less food. We speculate that the concentration of mistakes in arms containing more grain may be a result of steers avoiding arms with less grain until they are certain that all grain in other arms was consumed. If this is true, reference memory may be as important as working memory in choosing where to forage. Animals could avoid areas that contain fewer resources until other areas are determined to be depleted.

Both reference memory and working memory should be considered when studying animal distribution and grazing behavior. Bailey (1988) found that cattle have the ability to remember where they have foraged for periods up to 8 hours, and this indicates an accurate working memory. Results from the present study show that cattle can also develop a reference memory of locations that involve tags for different food amounts and utilize that information 24 hours later. Further studies are needed to determine if a memory-based (cognitive) mechanism is appropriate for predicting cattle grazing patterns.

\section{Literature Ctted}

Bailey, D.W. 1988. Characteristics of spatial memory and foraging behavior in cattle. Ph.D. Diss., Colorado State Univ., Fort Collins.

Bailey, D.W., L.R. Rittenhouse, R.H. Hart, and R.W. Richardy. 1987. Spatial memory of heifers in radial-and parallel-arm mazes. Proc., West. Sec. Amer. Soc. Anim. Sci. 38:7-10.

Beatty, W.M., and D.A. Shavalia. 1980. Spatial memory in rats: time course of working memory and effects of anesthetics. Behav. Neural Biol. 28:454-462.

Conover, W.J. 1980. Practical nonparametric statistics, 2nd Ed. John Wiley and Sons, New York, New York.

Cook, C.W. 1966. Factors affecting utilization of mountain slopes by cattle. J. Range Manage. 19:200-204.

Gillen, R.L., W.C. Krueger, and R.F. Mlller. 1984. Cattle distribution on mountain rangeland in northeastern Oregon. J. Range Manage. 37:549-553.

Honig, W.K. 1978. Studies of working memory in the pigeon. p. 211-248. In: S.H. Hulse, H. Fowler, and W.K. Honig (Eds.). Cognitive processes in animal behavior. Erlbaum, Hillsdale, New Jersey.

Hulse, S.H., and D.K. OLeary. 1982. Serial pattern learning: Teaching an alphabet to rats. J. Exp. Psychol. Animal. Behav. Processes 8:260-273.

Miller, R.F., and W.C. Krueger. 1976. Cattle use on summer foothill rangelands in northeastern Oregon. J. Range Manage. 29:367-371.

Muegeler, W.F. 1965. Cattle distribution on steep slopes. J. Range Manage. 18:255-257.

Olton, D.S. 1978. Characteristics of spatial memory. p. 341-373. In: S.H. Hulse, H. Fowler and W.K. Honig (Eds.). Cognitive Processes in Animal Behavior. Erlbaum, Hillsdale, New Jersey.

Roberts, W.A., and N. van Veldhuizen. 1985. Spatial memory in pigeons on the radial maze. J. Exper. Psychol. Anim. Behav. Processes 11:241-260.

Senft, R.L., M.B. Coughenour, D.W. Balley, L.R. Rittenhouse, O.E. Sala, and D.M. Swift. 1987. Large herbivore foraging and ecological hierarchies. Bioscience 37:789799.

Senft, R.L., L.R. Rittenhouse, and R.G. Woodmansee. 1983. The use of regression models to predict spatial patterns of cattle behavior. J. Range Manage. 36:553-557.

\section{Notice to Authors}

A FORM TO BE USED WHEN SUBMITTING MANUSCRIPTS is published on the last two pages of the Journal. A copy of this form must accompany all manuscripts submitted after July 1, 1989. 